\title{
Heart Rate Performance Curve Is Dependent on Age, Sex, and Performance
}

\begin{abstract}
Philipp Birnbaumer ${ }^{1}$, Heimo Traninger ${ }^{2}$, Andrea Borenich ${ }^{3}$, Markus Falgenhauer ${ }^{4}$, Robert Modre-Osprian ${ }^{4}$, Hanns Harpf ${ }^{2}$ and Peter Hofmann ${ }^{1 *}$

${ }^{1}$ Exercise Physiology, Training \& Training Therapy Research Group, Institute of Sports Science, University of Graz, Graz, Austria, ${ }^{2}$ ZARG Centre for Outpatient Rehabilitation, Graz, Austria, ${ }^{3}$ Department of Production and Operations Management, University of Graz, Graz, Austria, ${ }^{4}$ Center for Health \& Bioresources, AlT Austrian Institute of Technology GmbH, Graz, Austria
\end{abstract}

Introduction: The Heart Rate Performance Curve (HRPC) is neither linear nor uniform and related to B1-adrenoceptor sensitivity. As aging and exercise influence B1-adrenoceptors we suggested age, sex and performance effects on the HRPC. Aim of the study was to examine the effects of aging on the deflection of the HRPC in maximal incremental cycle ergometer exercise (CE) in a large cohort of healthy subjects.

OPEN ACCESS

Edited by:

Katherine Henrietta Leith, University of South Carolina,

United States

Reviewed by:

Alexjandro C. Daviano,

DynaMed Plus, EBSCO Health,

United States

Angela M. Goins,

University of Houston-Downtown,

United States

*Correspondence:

Peter Hofmann

peter.hofmann@uni-graz.at

Specialty section:

This article was submitted to

Aging and Public Health,

a section of the journal

Frontiers in Public Health

Received: 22 January 2020 Accepted: 11 March 2020

Published: 02 April 2020

Citation:

Birnbaumer $P$, Traninger $\mathrm{H}$, Borenich A, Falgenhauer M, Modre-Osprian R, Harpf $H$ and

Hofmann P (2020) Heart Rate Performance Curve Is Dependent on

Age, Sex, and Performance.

Front. Public Health 8:98.

doi: 10.3389/fpubh.2020.00098
Methods: Heart rate (HR) data of 2,980 men (51 \pm 15 years) and 1,944 women (52 \pm 14 years) were classified into age groups ( $\leq 20$ up to $>80$ years). We analyzed age and performance ( $\mathrm{P}_{\text {low }} 25 \%$-quartile and $\mathrm{P}_{\text {high }} 75 \%$-quartile of age predicted power) effects on $\mathrm{HR}_{\max }$ and on the degree $(k)$ and the type (regular downward deflection $k>0.1$, linear $-0.1 \leq k \leq 0.1$ and atypical upward deflection $k<-0.1$ ) of the HRPC.

Results: $k$-values decreased significantly with age in men and women and were significantly higher in women. Atypical HRPC's increased by a linear trend from $\leq 20$ to 70 years $(m)$ respectively 80 years $(w)$ from 10 to $43 \%(m)$ and 9 to $30 \%(w)$. $H_{\text {max }}$ of all age groups was lower in Plow and overall number of atypical HRPC's was $21 \%(m)$ and $16 \%(w)$ higher compared to Phigh.

Conclusion: Aging increased the number of atypical HRPC's with upward deflection in CE tests, which influences exercise intensity prescription especially when using fixed percentages of HRmax. Changes in HRPC's were affected by sex and performance, where women generally and subjects with higher performance presented less atypical HRPC's even at older age.

Keywords: heart rate deflection, B1-receptor sensitivity, intensity prescription, sex differences, maximal heart rate, aging

\section{INTRODUCTION}

Research in the past few years revealed, that the heart rate performance curve (HRPC) in incremental exercise is neither linear nor uniform (1), which was shown to have an impact on exercise prescription (2). With stepwise increasing intensity, heart rate increases progressively in an s-shaped manner which has already been shown by Brooke and Hamley (3). Later on, Conconi et al. (4) used the flattening of the heart rate during incremental exercise to determine a deflection point equivalent to the anaerobic threshold. Although there is no full agreement in literature about 
the reliability and validity of this method, Bodner and Rhodes (5) as well as Hofmann and Pokan (6) gave a comprehensive overview of its value.

Interestingly, a significant number of tests show a linear or even an inverted time course of the HRPC. Although most young healthy subjects $(\sim 86 \%)$ showed a regular deflection of the HRPC, in this homogenous group of 227 ( $23 \pm 4$ years) trained male sports students an inverse deflection was found in in $7.9 \%$ cases and a linear time course was found in $7.9 \%$ of subjects in this study (1). Additional information is sparse and only one study by Heber et al. (7) presented data on HRPC deflection in 128 patients during cardiac rehabilitation, however did not show the distribution among subjects. Pokan et al. (8) was the first to show increasing atypical HR curves in older patients suffering from heart disease. Converse to healthy subjects, most patients ( $86 \%$ ) showed an inverse deflection in the exercise tests administered $\sim 57$ days after myocardial infarction. A regular deflection was only found in $4 \%$ and a linear time course in $10 \%$.

Underlying physiological regulations such as a parasympathetic or sympathetic influences, as well as the relationship to left ventricular function on the degree and direction of HRPC deflection, have been investigated in several studies compiled in a review (6). The most plausible and actually valid explanation for the different HRPC patterns was found for $\beta 1$-receptor sensitivity shown by our study group (9). This hypothesis was supported most recently by results from cardio-pulmonary exercise testing in individuals with type 1 diabetes (10) where the degree of HRPC deflection was significantly lower in individuals with type 1 diabetes compared to matched controls. These authors concluded, that constantly elevated $\mathrm{HbA}_{1 \mathrm{c}}$ levels and concomitantly elevated catecholamine levels and/or inflammation induced chronic stress impairs $\beta 1$-receptor sensitivity, which alters the degree and direction of the HRPC. Such a pathophysiological value of the HRPC can also be found in patients after myocardial infarction, who frequently present an upward deflection in incremental exercise tests (11). A normalization of the HRPC was found with increasing cardiorespiratory fitness after a 1 year exercise-based cardiac rehabilitation program independent from medication (7).

As the pattern of the HRPC has substantial consequences for the prescription of exercise intensity it was argued that using the same fixed percentage of maximal heart rate $\left(\mathrm{HR}_{\max }\right)$ will result in different workloads with respect to the anaerobic threshold (12). Subjects with an atypical HRPC are prone to overload compared to subjects with regular HRPC's $(2,13)$.

A well-examined factor influencing $\mathrm{HR}_{\max }$ is age. From the age of 18 to 50 years, $\mathrm{HR}_{\max }$ was shown to decrease linearly by 0.7 beats $\cdot \mathrm{yr}^{-1}$, with a smaller decrease in younger adulthood (14). Several reasons for this decrease in $\mathrm{HR}_{\max }$ with age have been discussed, although no definite conclusion has been drawn yet. Beside the age associated decline in cardiac autonomic function (15) and a reduction of intrinsic heart rate $\left(\mathrm{HR}_{\mathrm{int}}\right)$ with age $(16)$, one main reason may be a reduced $\beta$-adrenoreceptor sensitivity or density with cardiac aging. Studies examining the cardiovascular effects to graded isoproterenol and propranolol infusions showed a reduced $\beta$-adrenergic responsivity with advancing age (1618). This could be addressed to age associated reductions in $\mathrm{HR}_{\max }(16)$.

Regarding the influence of exercise, even high levels of daily physical activity had no effects on heart rate response with respect to age (15). On the other hand, Rogers et al. (19) showed no decrease in maximum heart rate in welltrained master endurance athletes in a period of 8 years of continues training compared to sedentary controls. This is in line with other results, which showed a slower rate of decline in $\mathrm{HR}_{\max }$ in people with higher cardiorespiratory fitness (20). Nevertheless, cardiorespiratory fitness declines non-linear up to 45 years followed by an accelerated decline with increasing age (21).

These well-known age-related changes in $\mathrm{HR}_{\max }$ are therefore also suggested to alter the pattern of the HRPC during aging. Hence, the aim of this study was to examine the effect of aging on the deflection of the HRPC in a large cohort of healthy male and female subjects. We hypothesized that the number of atypical HRPC's is increasing with age but different between sexes and modulated by exercised performance.

\section{METHODS}

This study was performed within the "HEALTHeBIKES" project in order to classify potential users by their $\mathrm{HR}$ response to exercise and to investigate whether programming a HR based ebike control is depending on age. The study has been approved by the Ethics Committee of the local University.

Heart rate and performance data from 30,000 cycle ergometer tests carried out for performance diagnostic, health preventive or medical reasons between 2004 and 2017 were obtained. Generally, this tests last about $15 \mathrm{~min}$ and individuals were encouraged not to do any vigorous activity the day before. Finally, 2,980 healthy men (age: $51 \pm 15$ years., range $13-87$ years) and 1,944 women (age: $52 \pm 14$ years, range from 13 to 89 years) who performed the same test protocol were included in the study. Only tests with correct HRPC presentation (no outliers or interruptions of $\mathrm{HR}$ recordings) and a $\mathrm{HR}_{\max }$ within $15 \%$ of the expected $\mathrm{HR}_{\max }$ calculated as 210-age were included in our analysis. The test protocol was uniform and independent from age, gender and performance and was applied according to the recommendations of the local Society of Cardiology (22). All ergometer tests started at $20 \mathrm{~W}$ and power was increased in uniform $20 \mathrm{~W}$ increments per minute up to exhaustion. In our retrospective analysis, we categorized the tests into eight age groups starting with $\leq 20$ years up to $>80$ years (Table $\mathbf{1}$ ). The degree and the direction of the HRPC deflection was calculated by a second-degree polynomial fit curve (least error square) (8) from the mean HR of each single load-step between 40 and $100 \%$ of $\mathrm{P}_{\max }$ (Figure 1). From this quadratic function the slopes $\left(\mathrm{k}_{1}\right.$ and $\mathrm{k}_{2}$ ) of the tangents $\left(\mathrm{t}_{1}\right.$ and $\left.\mathrm{t}_{2}\right)$ in the two HR-points of the curve corresponding to 40 and $100 \% \mathrm{P}_{\max }$ were calculated. With the slopes of these two tangents the type of deflection was determined by using the factor $k\left(k=\left(k_{1}-k_{2}\right) /\left(1+k_{1 *} k_{2}\right)\right)$. 
TABLE 1 | Number of tests $(N)$ and mean \pm SD age, BMl, body mass $(B M)$ and $\% \mathrm{P}_{\max }$ of each age group in men and women.

\begin{tabular}{|c|c|c|c|c|c|c|c|c|}
\hline Men $(2,980)$ & $\leq \mathbf{2 0}$ & $21-30$ & $31-40$ & $41-50$ & $51-60$ & 61-70 & $71-80$ & $>80$ \\
\hline N & 105 & 236 & 455 & 651 & 670 & 555 & 271 & 37 \\
\hline Age (years) & $17.8 \pm 1.8$ & $26.0 \pm 2.8$ & $36.1 \pm 2.9$ & $45.8 \pm 2.8$ & $55.3 \pm 2.9$ & $65.3 \pm 2.9$ & $74.3 \pm 2.5$ & $83.2 \pm 1.8$ \\
\hline BM (kg) & $72.4 \pm 10.7$ & $79.2 \pm 12.9$ & $83.2 \pm 12.2$ & $85.0 \pm 11.5$ & $85.4 \pm 12.5$ & $82.5 \pm 11.5$ & $81.1 \pm 11.6$ & $77.2 \pm 10.6$ \\
\hline$\% P_{\max }(\%)$ & $108 \pm 18$ & $114 \pm 21$ & $124 \pm 24^{*}$ & $120 \pm 21$ & $122 \pm 20$ & $119 \pm 22$ & $112 \pm 19^{*}$ & $105 \pm 18$ \\
\hline Age (years) & $18.2 \pm 1.8$ & $26.2 \pm 2.7$ & $36.4 \pm 2.8$ & $45.9 \pm 2.9$ & $55.2 \pm 2.9$ & $65.1 \pm 2.8$ & $74.4 \pm 2.6$ & $83.4 \pm 1.9$ \\
\hline BMI $\left(\mathrm{kg} / \mathrm{m}^{2}\right)$ & $22.0 \pm 2.8$ & $22.1 \pm 3.7$ & $23.0 \pm 3.9$ & $24.0 \pm 4.3^{*}$ & $25.2 \pm 4.2^{*}$ & $25.8 \pm 3.9$ & $25.8 \pm 4.0$ & $25.5 \pm 3.4$ \\
\hline BM (kg) & $62.4 \pm 9.3$ & $61.6 \pm 11.1$ & $64.3 \pm 11.6$ & $66.5 \pm 12.4$ & $68.5 \pm 12.3$ & $68.5 \pm 10.7$ & $68.1 \pm 11.2$ & $65.1 \pm 8.8$ \\
\hline$\% \mathrm{P}_{\max }(\%)$ & $125 \pm 18$ & $129 \pm 18$ & $127 \pm 23$ & $126 \pm 21$ & $119 \pm 19^{*}$ & $111 \pm 20^{*}$ & $101 \pm 18^{*}$ & $93 \pm 17$ \\
\hline
\end{tabular}

*Significant different compared to the previous younger age group.

$N$ denote the number of analyzed tests.

$\% P_{\max }$ denotes $P_{\max }$ in percent of age predicted power $\left(P_{\text {pred }}\right)$ which was calculated for men: $P_{\text {pred }}=6,773+136,141 * B S-0.916 * B S * a g e$ and women: $P_{\text {pred }}=3,933+$ $86,641 * B S-0.346 * B S * a g e$ whereby BS denotes body surface calculated as: $B S=0.007148 * B W(\mathrm{~kg})^{0.425} \cdot H(\mathrm{~cm})^{0.725}(23)$.
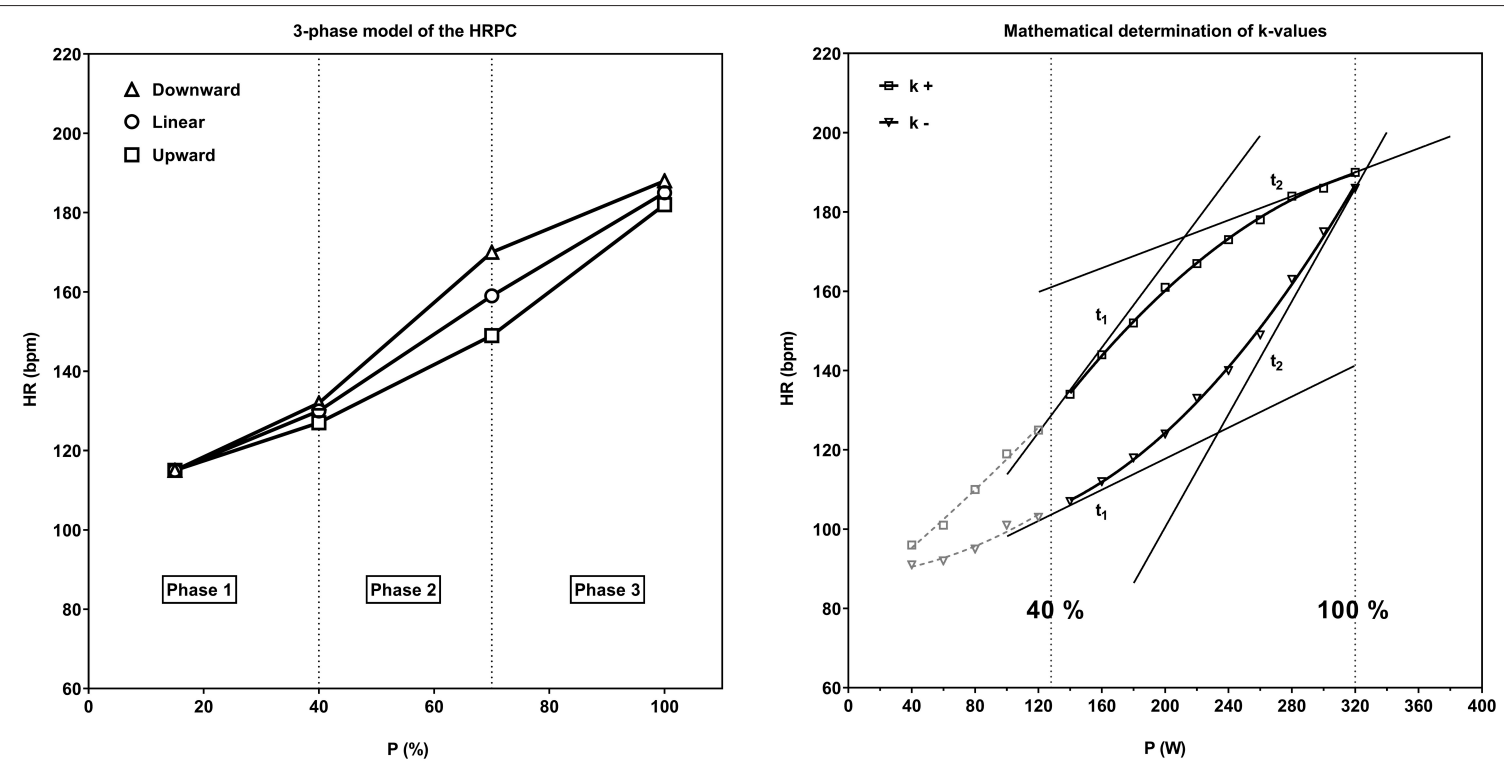

FIGURE 1 | Schematic 3-phase model of the HRPC from incremental cycle ergometer exercise with regular downward deflection, linear time course and upward deflection (1). Mathematical determination of $k$-values from HRPC's with downward $(k+)$ and upward deflection $(k-)$. The degree and the direction of the HRPC deflection ( $k$ ) was calculated from the difference of angles of the tangents $\left(t_{1}, t_{2}\right)$ from a polynomial best fit between 40 and $100 \%$ of $P_{\max }(8)$.

$k$-values were classified as downward deflection $k+(k>0.1)$ (regular), linear $k 0(-0.1 \leq k \leq 0.1)$ and upward deflection $k-$ $(k<-0.1)$ (atypical) (Figure 1).

Furthermore, $\mathrm{P}_{\max }$ in percent of age predicted power $\left(\% \mathrm{P}_{\max }\right)$ was calculated using a standard equation (Table 1) from the local cardiological society (22). To assess the effect of performance on $\mathrm{HR}$ deflection and $\mathrm{HR}_{\max }$ we compared subjects with low ( $\mathrm{P}_{\text {low }}: 25 \%$-quartile) and high ( $\mathrm{P}_{\text {high }}$ : $75 \%$-quartile) performance $\left(\% \mathrm{P}_{\max }\right)$ within each age group.

\section{Data Analysis}

Data Analysis was performed using GraphPad Prism 7 (GraphPad Software, San Diego, CA). For confirmation of normality, the Shapiro-Wilk normality test was used. Repeated measures ANOVA with Dunn's multiple comparison test was used to compare $k$-values, $\mathrm{HR}_{\max }, \mathrm{P}_{\max }, \% \mathrm{P}_{\max }$, and $\mathrm{BMI}$ between age groups. Linear regression analyses were performed to prescribe the age-related changes of the HRPC and the absolute $k$-values. Data are presented as means \pm SD. Statistical significance was set at $p<0.05$.

\section{RESULTS}

The number of analyzed tests as well as the mean age, BMI and body mass of each age group are shown in Table 1. Maximum HR decreased linearly with age ( $m: \mathrm{HR}_{\max }=212-0,93 *$ age, $r=0.82$; 
$w: \mathrm{HR}_{\max }=205-0.85 *$ age, $\left.r=0.80\right)$ from $191 \pm 9 \mathrm{bpm}(m)$ to 185 $\pm 7 \mathrm{bpm}(w)$ in the youngest age group to $133 \pm 8 \mathrm{bpm}(m)$ and $128 \pm 9 \mathrm{bpm}(w)$ in the oldest age group (Figure 2). The mean decrease per decade of both groups was $8.2 \pm 1.9 \mathrm{bpm}$, whereas the $\mathrm{HR}_{\max }$ decrease was less in subjects younger than 50 years $(6.5 \pm 1.3 \mathrm{bpm})$ compared to subjects older than 50 years $(9.5$ $\pm 1.3 \mathrm{bpm})$. Correlation analyses of $\mathrm{HR}_{\max }$ and age-predicted maximum heart rate calculated from Tanaka et al. (24) $\left(\mathrm{HR}_{\max }\right.$ $=208-0.7 *$ age $)$, were comparable and significant $(r=0.81)$.

Maximum power was unaffected by age up to 50 years in men $\left(\mathrm{P}_{\max }=253 \pm 49 \mathrm{~W}\right)$ and women $\left(\mathrm{P}_{\max }=165 \pm 29 \mathrm{~W}\right)$ and decreased significantly in the older age groups. The lowest $\mathrm{P}_{\max }$ ( $m: 126 \pm 22 \mathrm{~W} ; w: 93 \pm 16 \mathrm{~W}$ ) was present in the oldest age groups ( $>80$ years) (Figure 2 ). Mean $\% \mathrm{P}_{\max }$ varied between age groups and decreased with increasing age. Except for the oldest female age group, mean $\% \mathrm{P}_{\max }$ was above $100 \%$, which means normal with respect to the given guideline norms (22) in every age group.

\section{Age Dependent Effects on HRPC}

The HRPC pattern significantly changed with increasing age both in men and women indicated by a significant decrease (ANOVA) of $k$-values in age groups $>31$ years $(m)$ and $>41$ years $(w)$ compared to subjects $\leq 20$ years. In the older age groups $k$ was not significantly different in men from 51 to 80 years and in women from 41 to $>80$ years. The highest $k$-values $\left(k_{\mathrm{m}}=0.25 \pm 0.24\right.$ / $\left.k_{\mathrm{w}}=0.44 \pm 0.33\right)$ were found in the youngest age groups $(\leq 20$ years). $k$-values were significantly higher in women compared to men. In men mean values even reached negative values in age groups older than 50 years which indicates an increasing number of atypical inverted HRPC's (Figure 3).

Figure 4 shows the distribution of $k$-values, categorized as regular downward deflection $(k+)$ as well as atypical upward $(k-)$ and linear HRPC deflection $(k 0)$. The number of heart rate curves with upward deflection increased from 10 to $43 \%$ in men $\leq 20$ to 70 years, but decreased slightly between 71 and 80 years and substantial in the oldest age group $>80$ years. In women, the number of atypical curves was smaller compared to men and increased from 9 to $30 \%$ for $\leq 20$ to 80 years with a smaller increase from 51 to 80 years, but also decreased in the age group $>80$ years. The increase of atypical curves with age shows a linear trend up to 80 years. Conversely, the number of cases presenting a regular downward deflection decreased from 75 to $52 \%(\mathrm{~m})$ and 85 to $49 \%(w)$ for subjects $\leq 20$ to 60 years and increased slightly from 61 to $>80$ years in both groups with a large increase in men $>80$ years. The number of linear curves was less affected by age.

\section{Exercise Performance and HRPC}

Assessment of 25 and $75 \%$-quartile of $\% \mathrm{P}_{\max }$ revealed a mean limit of all age groups for the lower quartile $\left(\mathrm{P}_{\text {low }}\right)$ at $102 \pm 6 \%$ $(m) / 103 \pm 12(w) \% \mathrm{P}_{\max }$ and for the upper quartile $\left(\mathrm{P}_{\text {high }}\right)$ at $128 \pm 6 \%(m) / 128 \pm 14(w) \% \mathrm{P}_{\max }$. $\mathrm{HR}_{\max }$ was lower in $\mathrm{P}_{\text {low }}$ compared to $\mathrm{P}_{\text {high }}$ of the single age groups, whereby $\mathrm{HR}_{\max }$ was significantly different in men between $>40$ to 70 years and in women between $>30$ to 70 years. The overall mean difference was $6 \pm 2 \mathrm{bpm}(m)$ and $7 \pm 2 \mathrm{bpm}(w)$. Higher $k$-values were found in $\mathrm{P}_{\text {high }}$ in age groups $>20$ to 70 years $(\Delta \mathrm{k}=0.15 \pm 0.04)$ in men and $<20$ to 60 years $(\Delta \mathrm{k}=0.16 \pm 0.08)$ in women. $k$ Values were significantly different for male subjects between $>20$ to 60 years and for female between $>20$ to 30 and $>40$ to 50 years. The number of curves with atypical upward deflection was higher in $\mathrm{P}_{\text {low }}$ compared to $\mathrm{P}_{\text {high }}$ in men and women except for the age groups $>70$ to 80 years. The increase of atypical curves was delayed to older age in $\mathrm{P}_{\text {high }}$ (Figure 5).

\section{DISCUSSION}

Our analysis of a large cohort of age and performance heterogenous healthy male and female subjects confirm previous results that the HRPC in incremental exercise tests is neither uniform nor linear $(1,2)$ and the well-known decrease of $\mathrm{HR}_{\max }$ with age. For the first time we show significant age related changes of the pattern of the HRPC with an increase in the number of atypical curves with an upward inflection of HR. These changes were significantly different between men and women and exercise performance had some minor effects on $\mathrm{HR}_{\max }$ and the pattern of the HRPC.

Comparable to our older results in young healthy male trained subjects (1), young subjects in our study presented the highest number of regular HRPC's with a downward deflection, suggested as "normal." However, our study group had a lower number of regular HRPC's in subjects in the same age group. Toward an age of 50 years changes in the degree of the HRPC deflection and the number of atypical curves were stronger compared to $>50$ years. Sparse studies showed that patients with cardiovascular disease mostly displayed an upward deflection of the HRPC $(7,11)$, prescribed also in people with type 1 diabetes (10), however no studies in age heterogenous healthy subject have been presented so far.

\section{B1-Receptor Sensitivity}

The decrease in $\mathrm{HR}_{\max }$ with age was comparable with recent studies $(14,24)$. As the decrease of $\mathrm{HR}_{\max }$ with age was associated with $\beta$-receptor insensitivity (16-18) and/or reduction in receptor density (25) this suggests a causal relation between the changes of the HRPC deflection with age and $\beta 1$-adrenergic receptor function. A reduced receptor sensitivity was shown to blunt the heart rate response at moderate exercise intensity where catecholamine levels are still low (26). At higher intensities catecholamine levels increase exponentially and thus receptors can be stimulated, increasing HR disproportionally compared to the smaller increase at low to moderate exercise intensity. This phenomenon was prescribed to cause an upward deflection of the HRPC (9)

\section{Sex Differences}

The overall number of atypical curves ( $m: 33 \%, w: 21 \%)$ and the degree of the HRPC deflection was different for men and women, who presented a comparable decrease of $\mathrm{k}$, but women had significantly higher values throughout the whole age span. These sex differences in the deflection of the HRPC can also be assigned to varied responses of men and women to $\beta$-adrenergic stimulation shown by isoproterenol infusion $(23,27)$. Men had a greater 


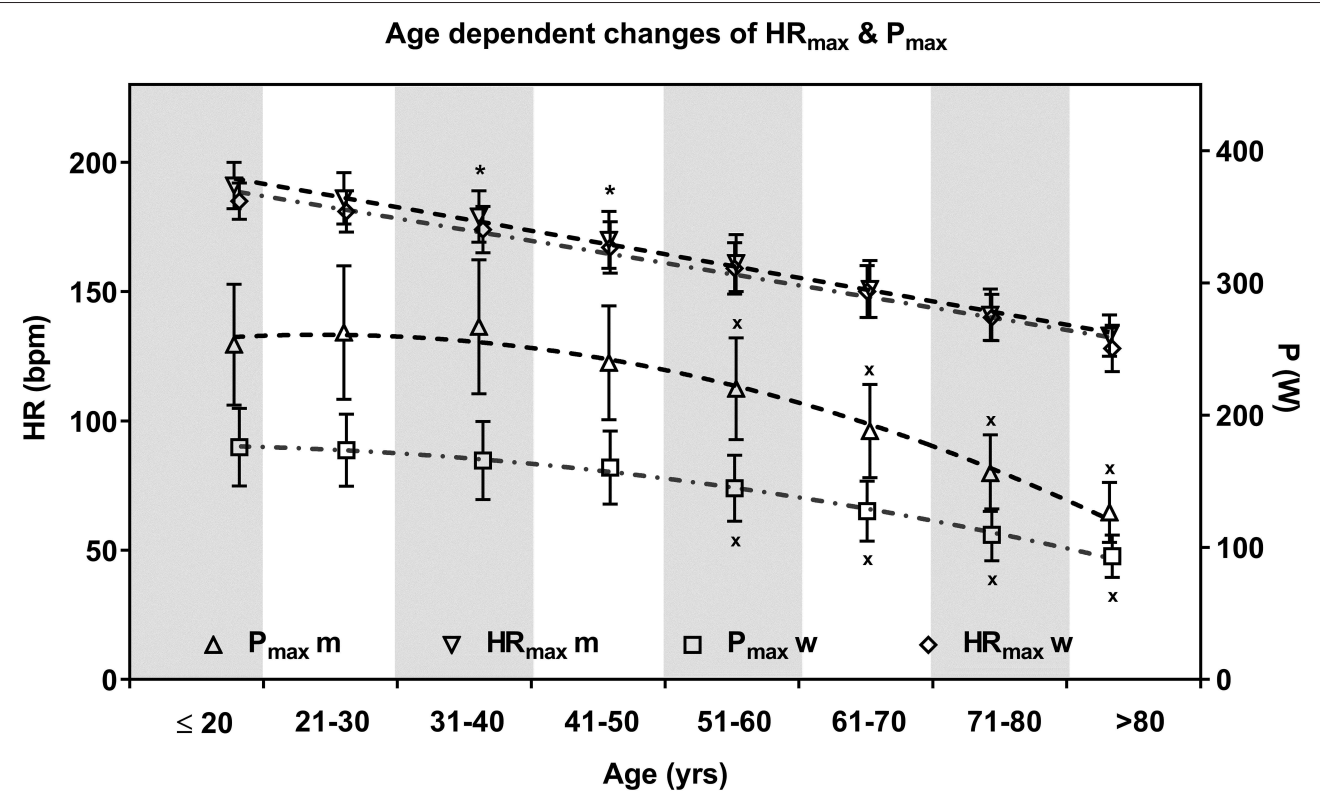

FIGURE 2 | Mean \pm SD maximum heart rate $\left(H R_{\max }\right)$ and power $\left(P_{\max }\right)$ of the age groups in men and women. Age course of HR $\mathrm{H}_{\max }$ is described via linear regression and $\mathrm{P}_{\max }$ via quadratic function. Men and women were significantly different for $\mathrm{P}_{\max }$ within each age group but not for $H R_{\max }$ except for two age groups. Aging was significantly related to decreasing $\mathrm{HR}_{\max }$ within each age group and decreasing $\mathrm{P}_{\max }$ in the age groups older 50 years in men and women. * significant different $H R_{\max }$ between men and women; ${ }^{\times} P_{\max }$ significant different from repeated measure ANOVA $(p<0.05)$.

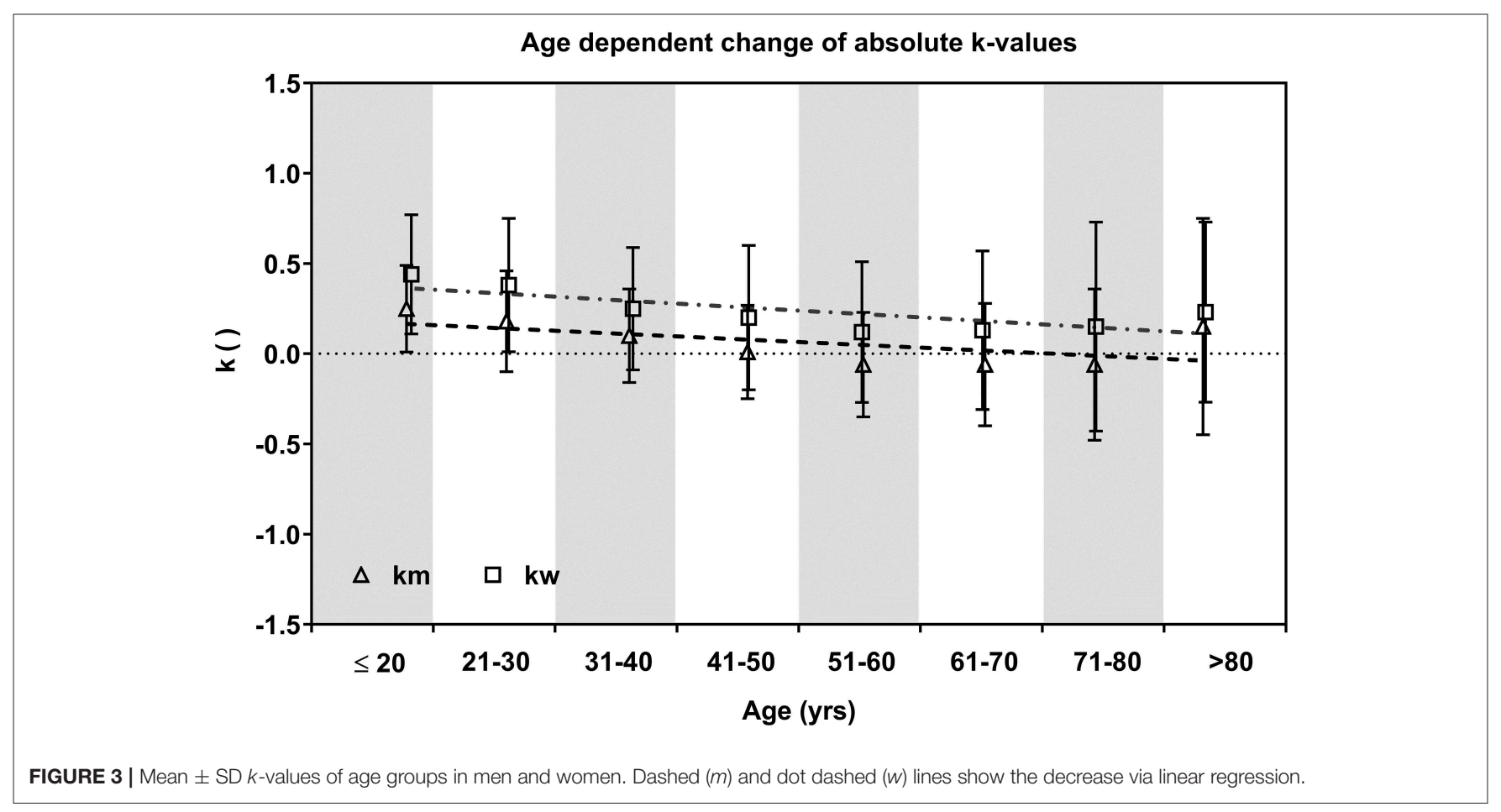

age-associated decrease in inotropic and chronotropic responses to catecholamines compared to women (23). In addition, $\beta$-adrenergic responsiveness was higher in young and older women compared to male reference groups (27). Referring to the causal relation between the deflection of the HRPC and $\beta 1$-adrenergic receptor sensitivity, this may explain the higher number of regular HRPC's in women. Beside B1adrenoceptor sensitivity women were shown to have differences in autonomic functions (28) although intrinsic HR may not be that important (29). 

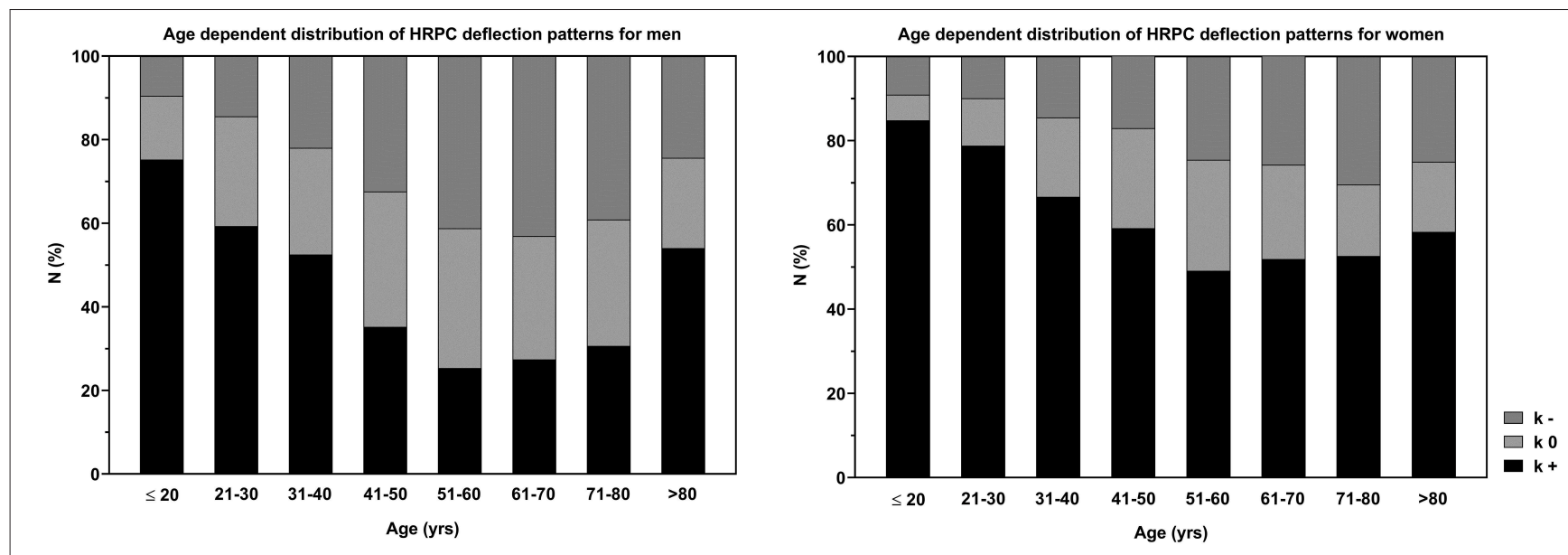

FIGURE 4 | Distribution of the HRPC deflection pattern (regular downward deflection: $k+$, atypical upward deflection: $k-$, linear heart rate deflection: $k 0$ ) for all age groups in men and women.
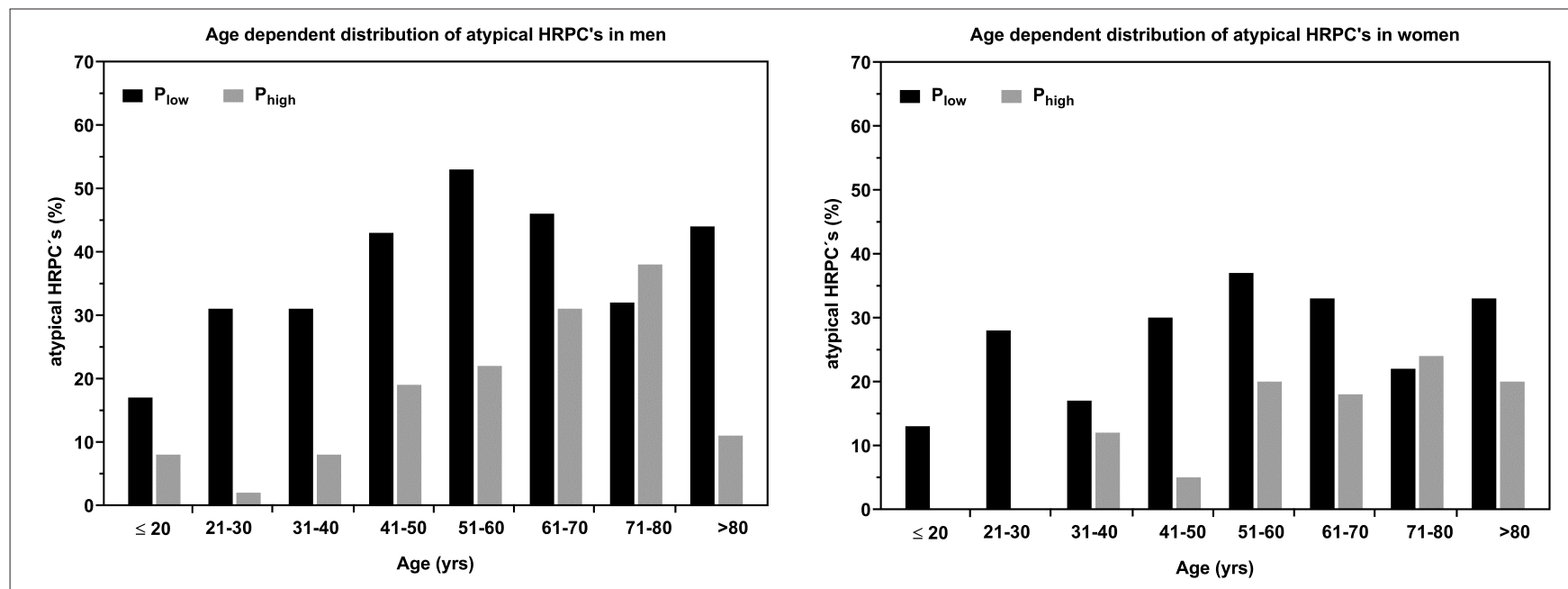

FIGURE 5 | Age dependent relative number (\%) of HRPC's with atypical upward deflection for high ( $\left.P_{\text {low }}\right)$ and low $\left(P_{\text {high }}\right)$ exercise performance groups (25\% respectively $75 \%$-quartile $\left.\% \mathrm{P}_{\max }\right)$ for men and women.

\section{Performance Differences}

Classification into low- and high-performance groups revealed lower $k$-values in $5(\mathrm{~m})$ respectively $6(w)$ age groups in $\mathrm{P}_{\text {low. }}$. The number of atypical curves in each single age group was substantially higher in $\mathrm{P}_{\text {low }}$ compared to $\mathrm{P}_{\text {high }}$ except for male and female age groups $>70$ to 80 years. Overall the number of atypical curves was $21 \%(\mathrm{~m})$ and $16 \%(w)$ higher in $\mathrm{P}_{\text {low }}$ compared to $\mathrm{P}_{\text {high, indicating a delayed onset of physical }}$ frailty in the $\mathrm{P}_{\text {high }}$ (30). The distribution of atypical curves in the age groups $>70$ to 80 years might be due to a general higher number of subjects in good condition in this age group, however relative $\mathrm{P}_{\max }$ do not support this suggestion. Anyhow, this group is suggested as healthy "survivors" who already exceeded the age of expected healthy life years which might lower the physiological differences between the high and low performance group.
Lehmann et al. (31) showed that higher performance was related to better $\beta 1$-receptor sensitivity which supports our data showing that subjects with higher performance presented a higher number of regular curves in line with earlier results from our working group (9). Additionally, several studies showed improved $\beta$-adrenergic responsiveness after 12 weeks treadmill training in rats and reversed $\beta$-adrenergic disfunction due to restored cardiac receptor density after exercise (32). Also aerobic exercise training was shown to reduce circulating catecholamine's (33), which counteracts reduced $\beta$-adrenergic density due to overactivation of the sympathetic nervous system and concomitant chronic catecholamine stimulation (34). Thus, sensitization of the $\beta 1$-receptor through regular exercise might normalize atypical HRPC provoked by chronic stress due to diseases such as type 1 diabetes (10) or cardiovascular disease (11) as shown recently (7). 
Mean exercise performance of all single age groups, except for the oldest age group in women, was higher compared to the age predicted maximum power output which may be classified "normal." Further, maximum ergometer power output was constant up to 50 years which is in line with earlier findings (21), but different to guideline values, which present a continuous decrease with age $(22,35)$. The $\mathrm{P}_{\max }$ decline was independent from $\mathrm{HR}_{\max }$ as already shown (36). $\mathrm{HR}_{\max }$ though was lower in the low compared to the high-performance group. This might be due to higher performance motivation of well-trained subjects, but might also be caused by a higher $\mathrm{O}_{2}$ extraction and concomitant higher cardiac output due to a higher muscular aerobic capacity in the high-performance group (19). Our results are in line with other studies who showed reduced decline of $\mathrm{HR}_{\max }$ in people with high cardiorespiratory fitness and confirm that decreasing $\mathrm{HR}_{\max }$ with aging is to a certain extent preventable by higher performance levels $(19,20)$. Anyway, mean $\mathrm{P}_{\max }$ of our cohort up to 50 years was $253 \pm 49 \mathrm{~W}$ in men and 165 $\pm 29 \mathrm{~W}$ in women.

\section{Exercise Prescription}

From a practical point of view the heterogenous character of HRPC's has some consequences on exercise prescription when using fixed percentage of $\mathrm{HR}_{\max }$, already discussed in detail by our study group $(2,12)$ which was supported recently by Iannetta et al. (37). We could nicely show that the same relative intensity of $85 \% \mathrm{HR}_{\max }$ gave different workloads when related to the anaerobic threshold and this effect became even stronger with $\beta_{1}$-recepter antagonism application (13). The calculation of a fixed percentage consequently leads to an underestimation of the workload in regular HRPC's but an overestimation in upward deflecting atypical curves. The use of such a $\% \mathrm{HR}_{\max }$ method may overestimate training heart rate by at least $5-10 \%$ and up to $40 \%$ in single cases (12). Underestimation might cause absence of desired training effects, but overestimation of the workload presents some risks and could have major consequences in subjects suffering from a chronic disease. Iannetta et al. (37) supported this earlier results and concluded that "contemporary gold-standard methods for exercise prescription based on fixedpercentages of maximum values conform poorly to exercise intensity domains and thus do not adequately control the metabolic stimulus."

Due to the changes of the HRPC pattern with aging, an age dependent prescription of exercise intensity needs to be developed as usual linear equations are not appropriate. The given guideline range of $77-95 \% \mathrm{HR}_{\max }$ (38) to calculate the upper target training limits represent a wide spectrum of cardiorespiratory and metabolic responses (39), so to fulfill the needs for an individualized approach, individual thresholds need to be determined (37).

Some limits of the study are to be mentioned. The generalizability of our study is limited. Exercise tests were performed in external institutions in terms of medical screenings. For our analyzes only apparently healthy individuals with no recorded medication were used, but insufficient documentation and comorbidity cannot be fully excluded. Additionally, in this retrospective study the actual activity level or training regime was not controlled directly. Further the exercise protocol was independent from the individual performance. The number of HR points for analysis were therefore smaller in individuals with low $\mathrm{P}_{\max }$. This causes less accuracy in the calculation of absolute k-values, but does not affect the classification of deflection types. Talking about the strengths, to our knowledge this is the first study investigating the effect of age on the HRPC time course. The great number of subjects included allowed to draw some general conclusions in this large cohort of healthy men and women.

\section{CONCLUSION}

The number of atypical HRPC's presenting an upward deflection in a maximal incremental cycle ergometer exercise test increases with age. These changes were influenced by age, sex, and performance, where subjects with higher performance presented less atypical HRPC even at older age. Because the number of atypical curves substantially increased with age we suggest to modify linear percent $\mathrm{HR}_{\max }$ exercise prescription models as the chance to overestimate training intensity increases with age. Furthermore, the determination of the HRPC deflection is suggested to give additional information regarding the health and performance status of subjects. Further research should focus on more detailed analysis of different subgroups such as patients, suffering from different chronic diseases, as shown nicely by Heber et al. (7).

\section{DATA AVAILABILITY STATEMENT}

The datasets generated for this study are available on request to the corresponding author.

\section{ETHICS STATEMENT}

The studies involving human participants were reviewed and approved by Ethic Committee University of Graz, Universitätsplatz 3, 8010, Graz. Written informed consent to participate in this study was provided by the participants' legal guardian/next of kin.

\section{AUTHOR CONTRIBUTIONS}

$\mathrm{PH}, \mathrm{RM}-\mathrm{O}, \mathrm{HT}$, and $\mathrm{PB}$ conceived and designed the experimental plan. $\mathrm{PB}$ and $\mathrm{AB}$ analyzed the data. $\mathrm{PB}$ and $\mathrm{PH}$ drafted the manuscript. MF, $\mathrm{PH}, \mathrm{HH}$, and $\mathrm{PB}$ refined and approved the final manuscript. All authors proofread and accepted the final version of the manuscript.

\section{FUNDING}

The study was funded by Zukunftsfonds Steiermark.

\section{ACKNOWLEDGMENTS}

We acknowledge the financial support of the University of Graz for publishing. 


\section{REFERENCES}

1. Hofmann P, Pokan R, von Duvillard SP, Seibert FJ, Zweiker R, Schmid P. Heart rate performance curve during incremental cycle ergometer exercise in healthy young male subjects. Med Sci Sports Exerc. (1997) 29:762-8. doi: 10.1097/00005768-19970600000005

2. Hofmann P, Von Duvillard SP, Seibert FJ, Pokan R, Wonisch M, Lemura $\mathrm{LM}$, et al. \%HRmax target heart rate is dependent on heart rate performance curve deflection. Med Sci Sports Exerc. (2001) 33:1726-31. doi: 10.1097/00005768-200110000-00017

3. Brooke JD, Hamley EJ. The heart-rate-physical work curve analysis for the prediction of exhausting work ability. Med Sci Sports. (1972) 4:23-6.

4. Conconi F, Ferrari M, Ziglio PG, Droghetti P, Codeca L. Determination of the anaerobic threshold by a non-invasive field test in runners. J Appl Physiol. (1982) 52:869-73. doi: 10.1152/jappl.1982.52.4.869

5. Bodner ME, Rhodes EC. A review of the concept of the heart rate deflection point. Sports Med. (2000) 30:31-46. doi: 10.2165/00007256-20003001000004

6. Hofmann P, Pokan R. Value of the application of the heart rate performance curve in sports. Int J Sports Physiol Perform. (2010) 5:437-47. doi: 10.1123 /ijspp.5.4.437

7. Heber S, Sallaberger-Lehner M, Hausharter M, Volf I, Ocenasek H, Gabriel H, et al. Exercise-based cardiac rehabilitation is associated with a normalization of the heart rate performance curve deflection. Scand J Med Sci Sports. (2019) 29:1364-74. doi: 10.1111/sms.13462

8. Pokan R, Hofmann P, Preidler K, Leitner H, Dusleag J, Eber B, et al. Correlation between inflection of heart rate/work performance curve and myocardial function in exhausting cycle ergometer exercise. Eur J Appl Physiol Occup Physiol. (1993) 67:385-8. doi: 10.1007/BF003 76453

9. Hofmann P, Wonisch M, Pokan R, Schwaberger G, Smekal G, von Duvillard S. Betal-adrenoceptor mediated origin of the heart rate performance curve deflection. Med Sci Sports Exerc. (2005) 37:1704-9. doi: 10.1249/01.mss.0000176308.70316.cc

10. Moser O, Eckstein ML, McCarthy O, Deere R, Bain SC, Haahr HL, et al. Heart rate dynamics during cardio-pulmonary exercise testing are associated with glycemic control in individuals with type 1 diabetes. PLoS ONE. (2018) 13:e0194750. doi: 10.1371/journal.pone. 0194750

11. Pokan R, Hofmann P, von Duvillard SP, Beaufort F, Smekal G, Gasser R, et al. The heart rate performance curve and left ventricular function during exercise in patients after myocardial infarction. Med Sci Sports Exerc. (1998) 30:1475-80. doi: 10.1097/00005768-199810000-00002

12. Hofmann P, Tschakert G. Special needs to prescribe exercise intensity for scientific studies. Cardiol Res Pract. (2010) 2011:209302. doi: $10.4061 / 2011 / 209302$

13. Wonisch M, Hofmann P, Fruhwald F, Kraxner W, Hödl R, Pokan R, et al. Influence of beta-blocker use on percentage of target heart rate exercise prescription. Eur J Cardiovasc Prev Rehabil. (2003) 10:296-301. doi: 10.1097/00149831-200308000-00013

14. Zhu N, Suarez-Lopez JR, Sidney S, Sternfeld B, Schreiner PJ, Carnethon $\mathrm{MR}$, et al. Longitudinal examination of age-predicted symptom-limited exercise maximum HR. Med Sci Sports Exerc. (2010) 42:1519-27. doi: 10.1249/MSS.0b013e3181cf8242

15. Njemanze H, Warren C, Eggett C, MacGowan GA, Bates MGD, Siervo $\mathrm{M}$, et al. Age-related decline in cardiac autonomic function is not attenuated with increased physical activity. Oncotarget. (2016) 7:76390-7. doi: 10.18632 /oncotarget.12403

16. Christou DD, Seals DR. Decreased maximal heart rate with aging is related to reduced $\beta$-adrenergic responsiveness but is largely explained by a reduction in intrinsic heart rate. J Appl Physiol. (2008) 105:24-9. doi: 10.1152/japplphysiol.90401.2008

17. Stratton JR, Cerqueira MD, Schwartz RS, Levy WC, Veith RC, Kahn SE, et al. Differences in cardiovascular responses to isoproterenol in relation to age and exercise training in healthy men. Circulation. (1992) 86:504-12. doi: 10.1161/01.CIR.86.2.504
18. Fleg JL, Schulman S, O'Connor F, Becker LC, Gerstenblith G, Clulow JF, et al. Effects of acute beta-adrenergic receptor blockade on age-associated changes in cardiovascular performance during dynamic exercise. Circulation. (1994) 90:2333-41. doi: 10.1161/01.CIR.90.5.2333

19. Rogers MA, Hagberg JM, Martin WH, Ehsani AA, Holloszy JO. Decline in VO2max with aging in master athletes and sedentary men. J Appl Physiol. (1990) 68:2195-9. doi: 10.1152/jappl.1990.68.5.2195

20. Ozemek C, Whaley MH, Finch WH, Kaminsky LA. High cardiorespiratory fitness levels slow the decline in peak heart rate with age. Med Sci Sport Exerc. (2016) 48:73-81. doi: 10.1249/MSS.00000000000 00745

21. Jackson AS, Sui X, Hébert JR, Church TS, Blair SN. Role of lifestyle and aging on the longitudinal change in cardiorespiratory fitness. Arch Intern Med. (2009) 169:1781-7. doi: 10.1001/archinternmed. 2009.312

22. Wonisch M, Berent R, Klicpera M, Laimer H, Marko C, Pokan R, et al. Praxisleitlinien ergometrie. Aust J Cardiol. (2008) 15:13. doi: 10.5414/ATX0947

23. Turner MJ, Mier CM, Spina RJ, Schechtman KB, Ehsani AA. Effects of age and gender on the cardiovascular responses to isoproterenol. $J$ Gerontol A Biol Sci Med Sci. (1999) 54:B393-400. doi: 10.1093/gerona/54. 9.B393

24. Tanaka H, Monahan KD, Seals DR. Age-predicted maximal heart rate revisited. J Am Coll Cardiol. (2001) 37:153-6. doi: 10.1016/S0735-1097(00)01054-8

25. Ferrara N, Komici K, Corbi G, Pagano G, Furgi G, Rengo C, et al. $\beta$-adrenergic receptor responsiveness in aging heart and clinical implications. Front Physiol. (2014) 4:396. doi: 10.3389/fphys.20 13.00396

26. Chwalbinska-Moneta J, Krysztofiak H, Ziemba A, Nazar K, and KaciubaUściłko $\mathrm{H}$. Threshold increases in plasma growth hormone in relation to plasma catecholamine and blood lactate concentrations during progressive exercise in endurance-trained athletes. Eur J Appl Physiol Occup Physiol. (1996) 73:117-20. doi: 10.1007/BF00262819

27. Johansson SR, Hjalmarson $\AA$. Age and sex differences in cardiovascular reactivity to adrenergic agonists, mental stress and isometric exercise in normal subjects. Scand J Clin Lab Invest. (1988) 48:183-91. doi: 10.3109/00365518809085411

28. Convertino VA. Gender differences in autonomic functions associated with blood pressure regulation. Am J Physiol. (1998) 275:R1909-20. doi: 10.1152/ajpregu.1998.275.6.R1909

29. Burke JH, Goldberger JJ, Ehlert FA, Kruse JT, Parker MA, Kadish AH. Gender differences in heart rate before and after autonomic blockade: evidence against an intrinsic gender effect. Am J Med. (1996) 100:53743. doi: 10.1016/S0002-9343(96)00018-6

30. Booth FW, Zwetsloot KA. Basic concepts about genes, inactivity and aging. Scand J Med Sci Sports. (2010) 20:1-4. doi: 10.1111/j.1600-0838.2009.0 0972.x

31. Lehmann M, Dickhuth HH, Schmid P, Porzig H, Keul J. Plasma catecholamines, $\beta$-adrenergic receptors, and isoproterenol sensitivity in endurance trained and non-endurance trained volunteers. Eur J Appl Physiol Occup Physiol. (1984) 52:362-9. doi: 10.1007/BF00943364

32. Leosco D, Parisi V, Femminella GD, Formisano R, Petraglia L, Allocca E, et al. Effects of exercise training on cardiovascular adrenergic system. Front Physiol. (2013) 4:348. doi: 10.3389/fphys.2013.00348

33. Passino C, Severino S, Poletti R, Piepoli MF, Mammini C, Clerico A, et al. Aerobic training decreases B-type natriuretic peptide expression and adrenergic activation in patients with heart failure. J Am Coll Cardiol. (2006) 47:1835-9. doi: 10.1016/j.jacc.2005.12.050

34. de Lucia C, Piedepalumbo M, Paolisso G, Koch WJ. Sympathetic nervous system in age-related cardiovascular dysfunction: pathophysiology and therapeutic perspective. Int J Biochem Cell Biol. (2019) 108:29-33. doi: 10.1016/j.biocel.2019.01.004

35. Arstila M. Pulse-conducted triangular exercise-ECG test. A feed-back system regulating work during exercise. Acta Med Scand Suppl. (1972) 529:3-109.

36. Ozemek C, Whaley MH, Finch WH, Kaminsky LA. Maximal heart rate declines linearly with age independent of cardiorespiratory fitness 
levels. Eur J Sport Sci. (2017) 17:563-70. doi: 10.1080/17461391.2016. 1275042

37. Iannetta D, Inglis EC, Mattu AT, Fontana FY, Pogliaghi S, Keir DA, et al. A critical evaluation of current methods for exercise prescription in women and men. Med Sci Sports Exerc. (2019) 52:466-73. doi: 10.1249/MSS.0000000000002147

38. ACSM. ACSM's Guidelines for Exercise Testing and Prescription. 10th ed. Philadelphia, PA: Lippincot Williams \& Wilkins (2016).

39. Scharhag-Rosenberger F, Meyer T, Gässler N, Faude O, Kindermann W. Exercise at given percentages of VO2max: heterogeneous metabolic responses between individuals. J Sci Med Sport. (2010) 13:74-9. doi: $10.1016 /$ j.jsams.2008.12.626
Conflict of Interest: The authors declare that the research was conducted in the absence of any commercial or financial relationships that could be construed as a potential conflict of interest.

Copyright (c) 2020 Birnbaumer, Traninger, Borenich, Falgenhauer, Modre-Osprian, Harpf and Hofmann. This is an open-access article distributed under the terms of the Creative Commons Attribution License (CC BY). The use, distribution or reproduction in other forums is permitted, provided the original author(s) and the copyright owner(s) are credited and that the original publication in this journal is cited, in accordance with accepted academic practice. No use, distribution or reproduction is permitted which does not comply with these terms. 